section to section to find out what is "cooking" -if that is a proper word to use in this context! Indeed, I have sometimes been reproved for not attending to my own section more-but this, of course, is really the point that $\mathrm{I}$ an trying to make: I know what is going on in my own field, and this particular conference gives me an excellent opportunity of discovering parallel progress in other spheres and linking what is happening in my own field with themand of modifying my own ideas as necessary.

I do not think that we can afford to relax our efforts in this matter. For example, as new knowledge comes along, we must examine our own knowledge to see what parts of it can be discarded from the syllabus. I think, as it was once put, of "all the luggage packed during our education which is never unpacked in the whole of the rest of our lives". We must, too, where necessary, lengthen our courses of training; in the last few years we have, for instance, lengthened the period of training for our teachers. And we must investigate new methods of teaching, such as programmed learning-of which we heard earlier today-to see if they can help us. And, to relate the matter again to our own conference, we must be fully aware that the problem exists in the field of postgraduate studies.

I think, however, that we can claim that, here at least, we are fully aware of this problem and that this is shown by the nature of the Kent Postgraduate Medical Centre at Canterbury, which is, of course, sponsoring the conference along with the Consulting Physicians of the South-East Metropolitan Region and Pfizer Limited. The Medical Centre is a postgraduate centre. But it will bring together $\stackrel{\varrho}{c}$ members of the medical, dental and veterinary professions. Moreover, it will also bring together members of the same profession who 을 are engaged in very different aspects of it. $\frac{\bar{D}}{\bar{N}}$ This is the very kind of activity which in my $\frac{\bar{\sigma}}{\sigma}$ view can do so much to avoid at least some $\stackrel{\mathbb{Q}}{\Omega}$ of the dangers of specialization which $I$ have mentioned.

For similar reasons, I hope that the Centre $\vec{\circ}$ will continue to have strong links with our $\vec{\omega}$ general educational life in Kent; I hope in particular that it will have a fruitful relation- 8 ship with the Kent Education Committee, which has always tried to do so much for $\vec{A}$ higher education in all its forms-not only in the support it has given to the new University of Kent at Canterbury but in the development $\stackrel{\sim}{\infty}$ of its own colleges and in the granting of $\infty$ awards which cover a very wide range of studies - including, I should add, medical studies and nautical studies!

And now I have very great pleasure indeed in introducing to you Dr. John and Dr. Valerie Graves. They are the Hon. Directors of the or medical recording services and sound libras of the College of General Practitioners, and they are to talk on "The use of tape recordings in medical education"-again one of those methods which I mentioned earlier as being of such great-and increasing-value to those concerned with education.-Dr. John Graves and Dr. Valerie Graves.

\title{
THE USE OF TAPE IN MEDICAL TEACHING
}

\author{
John Graves, O.B.E., M.R.C.S., L.R.C.P. \\ Medical Recording Service and Sound Library, \\ College of General Practitioners, \\ Writtle, Chelmsford, Essex.
}

I HAVE used the word "teaching" rather than "education" because there are important differences. Education is a complicated process during which a student not only acquires facts but learns how to use them and to develop his own ideas Teaching is the actual process of transmission of facts, techniques and ideas from teacher to student, and it is with this process that I am concerned, using the word "student" in its widest sense to include postgraduates, general practitioners and other learners.
Teaching interests me for two quite different reasons: firstly, I run a library of tape recordings and so $I$ am interested in the production of teaching material. Secondly, I am a general $\mathrm{c}$ practitioner and therefore a perpetual student, always in need not only of new facts but also 0 of constant turning over of my basic knowledge, re-arranging it in the light of new medical ? thought. As a producer $I$ am interested in the quality of teaching material: as a consumer I am interested in whether that material is acceptable to the students for whom it is in- 
tended. Motivation plays a part in this-it is by no means the same in all groups. For instance, students want to pass examinations; postgraduates want to acquire special skills; general practitioners want practical information about how to treat their patients. It is futile to deplore these narrow motives-we must try to present the material in such a way that it is interesting in itself, so that the student is led on to want to find out more for himself: not to accept blindly, but to ask "Why?"

The first essential is to make the material attractive-we must pay attention to techniques of salesmanship. For what are teachers if not salesmen? Trying to persuade students to want something they do not yet possess? The desire to know more must be awakened. If students are bored or fail to understand they will not want to know however hard they try, and when the first curiosity is lost a kind of immunity is acquired to the subject that is hard to break down. We all know the glazed look that creeps over the faces of an audience towards the end of a long lecture. This spells bad teaching, not inattentive learning. We must make greater use of illustrations and try more positive approaches.

The student is not always aware himself that he is not learning-I have myself read the same pages of a certain textbook of pathology night after night without learning anything, and it was a long time before I realised that for me this was not the way to learn.

Different people learn, understand and remember in very different ways. We know very little about these differences, and much research is needed into methods of learning. For instance, I can remember a series of facts in sequence (such as a car route) better than my wife can, but she is better at putting a confusion of facts into order. I like to hear something explained: she likes to have it written down. I find a complicated diagram confusing unless I have seen it built up. When I was a student I learned very little from formal lectures and reading: I enjoyed the clinical teaching and it seemed logical, but I entirely failed to grasp many of the basic principles. I passed my examinations simply by learning things by heart, and I did not really understand what I had learned until I came to apply it to my own patients

I am sure that more than half of an ordinary average class of students have this difficulty in learning, and that this is why so many of them fail to keep up to date afterwards. The top $10 \%$ of any class are those who can learn most easily from standard methods, these students eventually become the teachers of the next generation: it probably never occurs to them that many of their students are quite unable to learn things in the same order and by the same techniques as they used themselves.

We may compare the facts of medical science to a field planted with cabbages: the student on first seeing this mass of facts will be daunted until he understands the principles on which they are arranged. The teacher knows the principles-he can visualise the neat, symmetrical rows, so many in this direction, so many in that. Because the pattern is so clear to him, he may not realise that many of his students cannot easily see it. Worst of all some may not realise that there is any pattern at all: they will be reduced to learning the facts by heart.

A philosophical question presents itself: are the top $10 \%$ more "intellectual" than the others? If so, is this important? They are probably better equipped for research, provided that they also have originality and patience. But are they the best choice as teachers? Almost certainly not, because they have difficulty in understanding how the mind of the average student works. A variety of types of mind is essential for the wide variety of work in the field of medicine. It is surely a pointless exercise to discuss which types, or which branches of medicine are more intellectual or more important: the most urgent need is to ensure that every student is actually learning what we intend him to learn. To do this we should make use of a much greater range of teaching techniques-including the various uses of tape-but above all we must check at every stage that the facts actually have been understood and remembered.

Perhaps the ideal standard approach to learning is as follows:

1. The basic principles should be presented in carefully prepared material, arranged according to previous experience of the most effective way of teaching these particular facts. When learning something for the first time it is probably better to hear it, in my experiencethe facts reach one with more impact. Tape is useful here, because a standard piece of teaching can be perfected and used over and over again, either for classwork or for students to hear in their own time.

2. Next, practical, visual or other supplementary material should be offered. Here I include work with apparatus, examination of patients, looking at photographs, slides, museum 
specimens and so forth. This would amplify and make real the principles that had been learned Selected reading would be included at this stage.

3. The students would then come together in small groups with a teacher to discuss what had been learned. It should not be possible for a student to pass this stage with ignorance unexposed. The teacher's presence is vital here and his time should not be wasted on standard teaching if this can be done by other means. We must not forget that students may not be aware of their own ignorance, or may be anxious to hide it so that they can proceed to the next subject.

4. The student might now be freed for personal exploration. He would follow up references (assuming that he had been taught how to do this); plan a piece of research or casework; go out on a project of his own.

5. A last stage would again gather the students for discussion and argument. At this final session the teacher would become aware of the attainments, personality and aptitude of each student and would be able to guide him in his future career or further study. Would not examinations then become redundant?

I would like to discuss some of the ways in which tape may be used for teaching. For example, there is the recorded talk. This may be straightforward instructional material; it may be designed to tell the general practitioner about new ideas; advice on how to handle patients (such as the technique of psychiatric history-taking) or how to explain illness to patients; the deliberately provocative talk, designed to start discussion; talks for doctors overseas and talks made by doctors in other lands; talks to describe and explain visual material such as photographs of skin conditions. ( $A$ number of recordings were played, some accompanied by illustrations, to demonstrate the different kinds of talk).

Talks of this kind are designed each for a particular purpose. They need careful scripting with particular attention to style and choice of words. They must be informal without being chatty-we attempt to create the illusion that the speaker is talking to the listener personally. Curiously enough this illusion is easier if the speaker cannot be seen

Some types of phrasing must be avoided. The active is better than the passive-"I prefer to use aspirin" rather than "Aspirin is the drug of choice" or "Treatment with aspirin is indicated." Phrases like "assume the recumbent posture" have crept into medical writing, but气 "lie down" is what the speaker would probably say in conversation, and he should be urged to avoid unnecessary jargon. Some words are ambiguous or difficult to hear: "invaluable" $\stackrel{\vec{F}}{\vec{*}}$ may be interpreted by an overseas listener with poor English as "valueless", and "hyper, hypo", 듬 "ante, anti" are traps for the ear.

Visual material such as tables and figures $\frac{\widehat{\Phi}}{\square}$ should not be read out but shown as illustrations: the use of slides widens the scope of tape ${ }^{\infty}$ enormously.

A successful talk needs considerable time $\overrightarrow{\vec{\omega}}$ and trouble. Good briefing is perhaps the greatest single factor, and good scripting the next. There is no doubt that some people are 3 . born speakers, but good production can $\mathrm{A}$ improve almost anyone, and the discipline of $\vec{A}$ writing a script and hearing what it sounds like can lead to a great improvement in one's general standard of teaching. Once a tape is $\infty$ completed it can be used over and over again: 옹 it is never tired, bored or ill, and when outof date it can be erased and used for another $\frac{D}{0}$ purpose with no ill-feeling.

Just as there are good speakers, so there age $\vec{\varphi}$ dull, indifferent and very bad speakers. The o often dislike teaching and have often had it thrust upon them. It is difficult to help the to make good recordings. But surely, famous guest speakers should be recorded for the benefit of posterity and the many people, $\stackrel{\circ}{\mathbb{Q}}$ including listeners overseas who would other- $\cong$ wise have no opportunity to hear them? $\overrightarrow{\overrightarrow{0}}$ Recordings made at meetings are often 3 acoustically poor and need ruthless editing, but they have actuality value and an ephemeral interest.

Recorded descriptive material is widely used now for visitors to historic buildings, using personal listening sets. This could be used in: pathology museums or to accompany sets of microscope slides. Complete teaching aidso could be made up in different languages for the use of developing countries.

An entirely different use of tape is the collection of recordings of medical sounds used $\mathrm{N}$ as illustrations in teaching. Such recordings $N$ make teaching more "live" and personal, 서 especially if combined with pictures. Theyo allow the student to hear sounds that he might not otherwise hear: they allow him to repeat $\frac{}{\Phi}$ the sounds over and over again until he? recognises the shape of them: they allow him 0 to compare one kind of sound with another.

Typical examples are heart and respiratory sounds; coughs; uterine and foetal heart sounds; $\stackrel{\mathbb{\perp}}{\odot}$ 
and sounds to illustrate a technique such as the induction of dental anæsthesia. We may use the voice of a patient telling his own story, to emphasize a point in teaching, or the voice itself may mean something to us-a few seconds listening to the actual voice of, for instance, a schizophrenic or depressed patient is worth many pages of text. The voice may be diagnostic of a condition, as in myxoedema and speech disorders. Tape may be used very dramatically, to demonstrate the effect of treatment on a disorder such as myasthenia gravis. Serial recordings may be made to show progress under treatment over a long period: well-made recordings can provide an unforgettable experience for students.

Tape may also be used for exhaustive detailed study of sounds-playing them more slowly, repeatedly or even backwards.

(Recordings were played to demonstrate these examples).

During the last few years, we have become very interested in group learning and in the small discussion group as a teaching method. It has its place at all levels of teaching but has many points to commend it for keeping general practitioners and other postgraduates up to date. A general practitioner suffers the great disadvantage that he does not have the same opportunities for academic argument as his colleagues in hospital. He may often meet other doctors, but talk tends to be about administrative or practical matters. It is easy for new ideas to pass him by, not because he does not hear of them but because among so many he does not know which are sensible and which are not. He tends to cling to the principles he learned in medical school until someone convinces him that they are wrong: if when he was a student he was not taught to challenge facts and argue about them, he will find it difficult to change his ideas.

It is often thought that general practitioners have difficulty in keeping up with new drugs. I do not think that this is true-the difficulty is in altering one's attitudes and ideas to accord with changes in medical thought. I remember how hard it was for me to accept that warmth was bad for shocked patients and exposure good for burns, when these ideas were first put forward. Revolutionary views are regarded with suspicion until someone personally known and trusted is seen to hold them himself: but every isolated doctor has the fear that he may be out of date without knowing it. The first step is to discover the limits of one's own ignorance, and the best way to do this is to argue a subject out with a

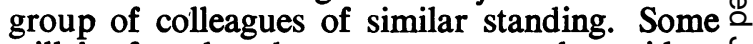
will be found to know more, some less: ideas $\subseteq$ can be pooled and perspective restored.

Such a group must be small-certainly not $\stackrel{\frac{9}{O}}{\frac{}{6}}$ more than ten -or some members will be left out and the intimate atmosphere will disappear. $\frac{\overline{\bar{c}}}{\bar{\alpha}}$ It must have a leader-preferably not the $\overparen{\otimes}$ most senior member-to keep discussion to the point and make sure that everyone takes part. क A teacher's presence may be helpful, but he $\vec{\circ}$ should not lead the group or it will degenerate $\overrightarrow{\vec{\omega}}$ into question and answer. Each member must $\stackrel{\sigma}{\omega}$ attend regularly and feel necessary to the group, $\vec{b}$ then a corporate spirit develops and members 3 . begin to follow points up and continue argument from week to week. They read more and become more active academically.

The group must have something definite to discuss. Many subjects are suitable-a case $\propto$ presentation, a film, a live speaker-but a tape 은 talk is particularly useful because it is so easy $\overrightarrow{ }$ to put on at any time or place, and the group $\frac{7}{0}$ is at liberty to criticise freely without offending the speaker. We have been amazed by the $\vec{\oplus}$ growth and popularity of these groups and bo of the demand for tapes for them to discuss. The subjects requested vary from the highbrow to the strictly practical, but the most successful talks are those that leave the listener slightly frustrated, perhaps slightly annoyed, wanting to know more and wanting to argue about it. An experienced group develops an aggressive enquiring spirit which brings its own dividends in terms of greater understanding, better cooperation between local doctors in hospital and practice, and increased efficiency.

General practitioners often tell us that they learn more from discussion groups than from going on a course, firstly because more is expected of them and mere passive acceptance is not possible, but also because the material is often better adapted to their needs. This does not mean that it is more low-brow or more "practical"-our Basic Medicine talks are among our most popular. It is sometimes forgotten that many ex-registrars enter general practice and are anxious not to sink out of touch with the academic world.

But one aspect of group teaching that we believe to be important is that it does bring in many of those who are in danger of sinkingthose who have never thought of going to courses, those who have lost interest in journals, or who are complacent and believe themselves well-informed, or the large number who know 
they are out of date but do not wish to expose their ignorance at a big meeting. We are often asked for a tape to give someone a general idea of a subject before he goes on a course. Discussion groups are also very useful for junior hospital staff or indeed for any learners provided that the group is small and all its members of similar status.

My wife and I have been running this library of tapes for the College of General Practitioners for nearly seven years. We started this service for a tiny group of isolated country doctors and could not then have believed that it would take root and grow in this way. We now produce talks ranging from First Aid for Nurses to Hydrogen Ion Regulation, and although our chief interest is still in general practitioners they now comprise only about half our listeners. In 1960 we sent out about 3 seven hundred tapes on loan: this year it will $\cong$ be seven thousand. Last year we had about $\stackrel{c}{.}$ twenty thousand known listeners in this $\overrightarrow{\vec{F}}$ country and overseas. We feel that this shows the enormous unsatisfied demand that there is $\frac{\mathrm{C}}{0}$ for teaching material of this kind, especially $\overline{\bar{c}}$. from the developing countries, and that $\bar{\nabla}$ teaching centres everywhere should be thinking about making use of this versatile and effective ${ }^{\infty}$ teaching tool. Universities, medical schools $\overrightarrow{0}$ and postgraduate centres have access to fine $\overrightarrow{-}$ speakers and first-hand information from the $\vec{\sigma}$ developing fringes of knowledge-these are needel all over the world. Tape can help to 3 . satisfy this need.

\title{
Third Session
}

\section{INTRODUCTION}

\author{
Geoffrey Templeman, M.A., Ph.D. \\ Vice-Chancellor, University of Kent at Canterbury
}

THE notion of postgraduate training over the whole field of higher education is now undergoing rapid change and extension. The kind of things that are happening in the field of medical education are also happening elsewhere. This is important because what the Postgraduate Medical Centre at Canterbury is trying to do is something which others in different circumstances are trying to do for the same reason. The matter could be put in this way. Until a few years ago over the whole field of higher education, postgraduate training had been thought of as something that followed quickly after the completion of an undergraduate course. Usually it took the form of a higher degree by research. Now this notion was breaking down. The breakdown happened because it was coming to be realised that, particularly in those areas where knowledge was advancing rapidly, graduates could not be expected to carry throughout the whole of their careers nothing more than as it were their original stock of knowledge gained, often long ago, when they were at the university, adding to it casually from reading they might have done thereafter. We had now to face the fact that in many fields and not only in medicine graduates had as it were to be regularly brought up-to-date in their own subjects. An example of this quite remote from medicines was to be found in science teaching in schools. Everyone knows that the biological sciences have advanced very considerably in the last few years and they are likely to advance even $\stackrel{\vec{F}}{\overrightarrow{2}}$ more in the immediate future. The great change $\frac{3}{3}$ there has been that these sciences have ceased to be descriptive and have become experimental. It is important that, particularly in sixth form work, this kind of new approach 3 . be reflected in the teaching given. In the last $\frac{0}{3}$ few years a number of the G.C.E. examining boards have found themselves faced with the problem of trying to produce new Advanced

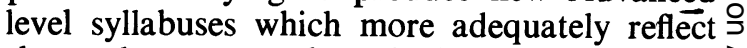
the modern approach to the biological subjects. $\frac{7}{0}$ The difficulty they have encountered has been in trying to persuade teachers, many of them $N$ trained in the older conception of the subject, $N$ to take hold of these syllabuses and to teach N them from a new angle. Here is a very clear $\omega$ case of a need to as it were bring the teachers up-to-date in their subject. Similarly in the $\frac{0}{\mathbb{D}}$ new and exciting experiments which are taking $\stackrel{\oplus}{?}$ place under the aegis of the Nuffield Foundation 0 in the teaching of mathematics and science the same kind of problem has to be faced in bringing those who will teach up-to-date in the 